\title{
THE GROWING ROLE OF ARTIFICIAL INTELLIGENCE IN HUMAN RESOURCE
}

\author{
Akanksha Saxena \\ Research Scholar, \\ Faculty of Commerce and Management, \\ Rama University, \\ Kanpur
}

Article DOI: https://doi.org/10.36713/epra4924

\begin{abstract}
The adoption and integration of technology with business is no longer a matter of choice but rather one of survival. Since times, businesses are aligning technology with business goals to ensure business continuity, survival and growth. Technological advancements have entirely reshaped and restructured the organization by making their business operations highly integrated and streamlined than even before. These technological advancements in business are bringing machines and humans more closely along with exploring ways of utilizing it to improve their productivity, ease and efficiency. The inclusion of Artificial Intelligence (AI) in business is an example of such business transformation.

The organizations that have already using Artificial Intelligence (AI) in their business operations have witness a progressive transformation of their core processes such as Supply chain and logistics management, marketing, finance, production and operation management, research and development $(R \& D)$ and other business operations, The Human Resource (HR) department is also not left behind in the race. Today the Human Resource (HR) professionals are focusing more on the importance of optimizing the combination of human and automated work for an intuitive work environment. As the organizations are adopting artificial intelligence into their Human Resource $(H R)$ process at a varying rate, it is important for the Human Resource $(H R)$ professionals to understand and prepare themselves for these technological changes, which are redefining their organization and workforce characteristics.

Artificial Intelligence (AI) based Human Resource (HR) technology help the organization to yield both short term and long term benefits. Artificial intelligence provides Human Resource (HR) departments to transform employee experience empowering managers to take consistent decisions solve critical business challenges, automating repetitive tasks, and building customized training module and assist Human Resource (HR) managers for taking more efficient decisions in talent development.

This research paper tries to underline the growing importance of Artificial Intelligence (AI) in human resource management (HRM) and aims to explain how artificial intelligence has been integrated into different functions of human resource. The researcher has used secondary data where the data was collected from research papers, publications, websites, HR blogs, survey reports etc. The research paper is descriptive in nature. The research study has concluded that Artificial Intelligence (AI) plays a significant role in carrying forward the Human Resource (HR) functions right from procurement to performance management and thus there is a growing need of integrating Artificial Intelligence (AI) in Human Resource Management (HRM).
\end{abstract}

KEYWORDS: - Artificial Intelligence (AI), Human Resource Management (HRM), Human Resource (HR).

\section{INTODUCTION}

The role of technology in the business panorama cannot be looked out. Since the time industrial revolution gained momentum, there has been a radical change in the way companies are doing business. Technology has become an indispensible and integral part of every business plan. Almost all the business owners count on technology to start and scale their companies. However, the paradigm of correlation between technology and business is not new. The traditional areas like process control, quality improvement, customer retention are replaced with modern and improved terminologies like business process reengineering, continuous improvement and total quality control, customer relationship building etc. Irrespective of the size of the business unit, technology provides tangible and intangible benefits to make the business profitable and meet the growing needs of the customer. The technological touch at every step of the end to end production process adds value for the customers. Businesses use an array of technology to develop competitive advantages in the economic marketplace and enhance their performance. The integration of technology with the business sector is one of the major factor for ensuring 
the success of the business (Trkman 2010, p. 130).As the digital world is emerging companies are trying to figure out as how they can shape the world around people with the use of the information technology tools. The digital era technological tools like Artificial Intelligence (AI), data analytics, Machine Learning(ML), Big Data, Internet of Things(IoT), Natural Language Processing, Cloud Computing etc. which began as a differentiating advantage are now be becoming the need of the hour for every business unit. The emerging technologies viz. internet of things (IoT), data science, big data, cloud computing, artificial intelligence (AI), and block chain are changing the way we live, work and amuse ourselves. Further advancement of these technologies can contribute in developing hyper automation and hyper connectivity, which would bring us at the dawn of the Fourth Industrial Revolution or Industry 4.0 (Schwab 2017; Bloem 2014; Klosters 2016; Park 2017). The business units that have invested in these tools have witness increased market share, financial figures and overall competitiveness. As the vision of the companies has been shifted to "show me" approach, the focus is also changing from promise to performance. If the business will not run parallel with the advancement in the technology, it will surely be left in the dust by one of the competitor. The broad spectrum of information technologies, uncovers also various possibilities for companies to use them as they conduct their exchanges. (Archer and Yuan, 2000).

Past researches have shown that Artificial Intelligence (AI) is speeding up exponentially and companies can no longer ignore is underlying potential. The advent of Artificial Intelligence (AI) has been predicted for decades but the catalyst for its emergence is the confluence of technology advances in the field of artificial neural networks, statistical algorithms, computing power and data analysis. .In India, the firms across diverse sectors such as healthcare, education, automobiles, banking and retail are increasing integrating Artificial Intelligence (AI) to transform their business. AI has been fostering business model innovation across industries including technology/media, consumer products, financial services, health care, industrial, energy, public sector, and so on (Serafini,2002). From data sales forecasting to decision making, fraud detection to customer retention, Artificial Intelligence (AI) is spreading its legs across almost every business sphere. According to a survey conducted by Tata Consultancy Service in 2017, Artificial Intelligence (AI) is contributing in business operations, major being in the Information Technology (IT) activities.

\section{How Companies Around the World Are Using Artificial Intelligence}

IT activities are the most popular.

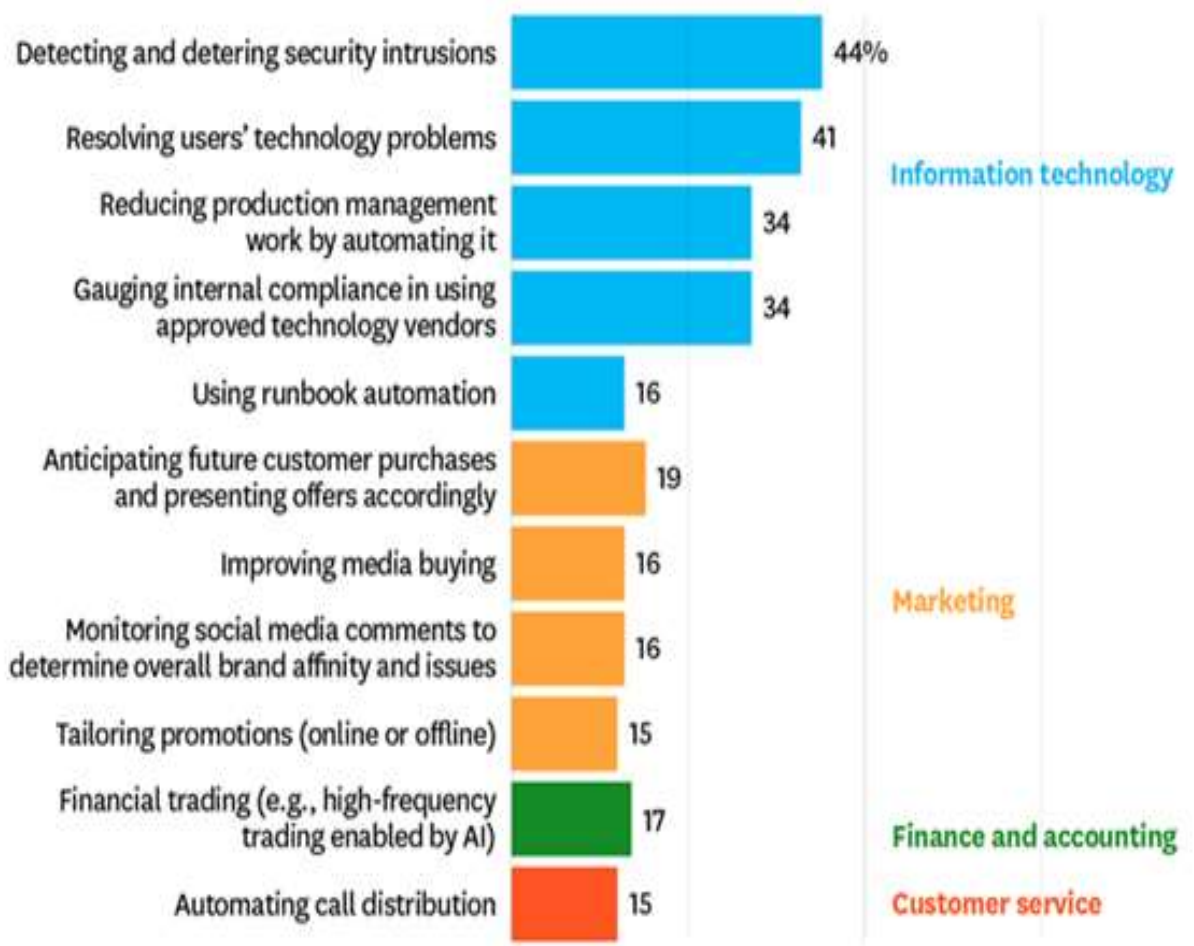

Chart 1: Use of Artificial Intelligence by different companies around the globe 


\section{II.REVIEW OF RELATED LITERATURE \\ 2.1 Artificial Intelligence}

The term Artificial Intelligence (AI) is composed of two words," Artificial" meaning "man made" and "Intelligence" meaning "the ability to acquire and apply knowledge and skills".

The concept of Artificial Intelligence (AI) is based on the assumption that the human thought process can be mechanised. Although designing machines to assist humans in their work was not a new concept, the discussion of machine's ability to exhibit intelligence gained momentum when Alan Turing, explored the mathematical possibility of machine learning. In his paper "Computing Machinery and Intelligence", Turning suggested that just the human use available information and logical reasoning to solve a problem and arrive at a decision, machines can replicate the same. However, the introduction of the concept of Artificial Intelligence

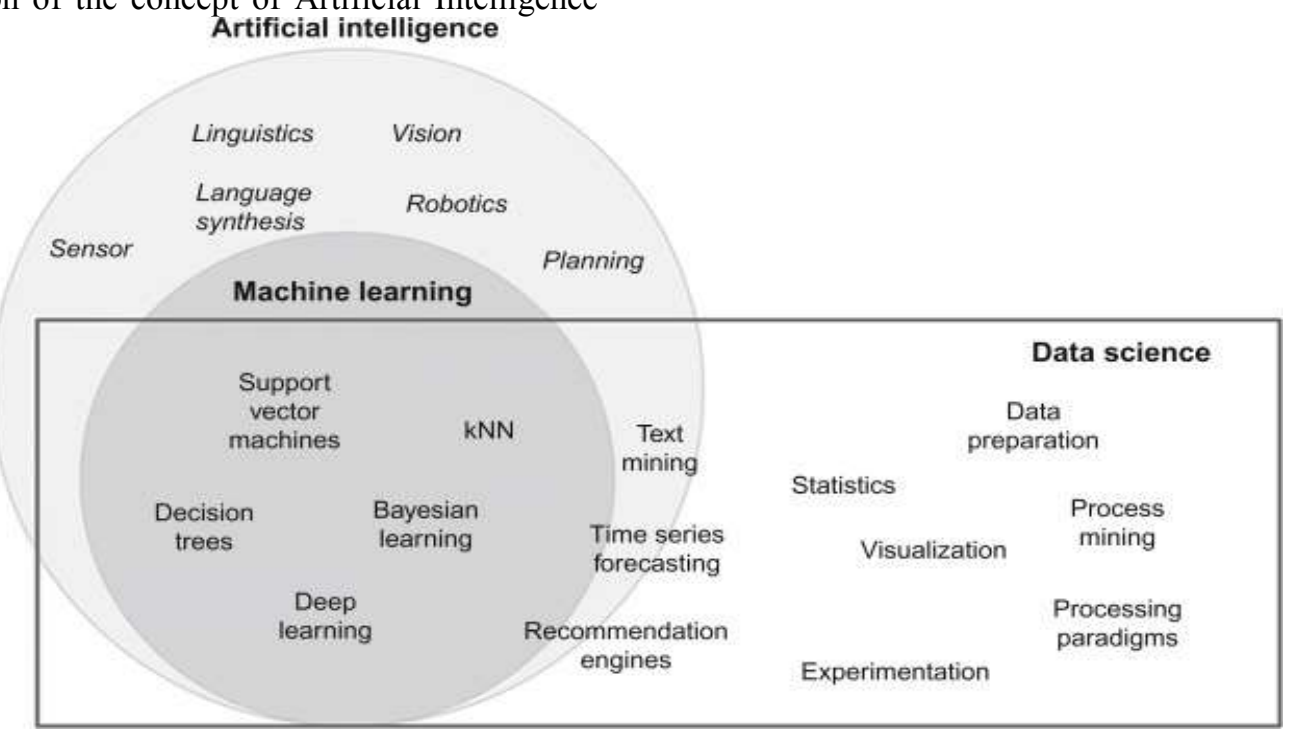

Figure 1 Relation between Artificial Intelligence (AI) and Machine Learning (ML)

(Source: Vijay Kotu, Bala Deshpande, in Data Science (Second Edition), 2019)
The massive and growing data today have generated numerous application of Artificial Intelligence (AI) across many diverse industries. Artificial intelligence is a tool which use human intelligence in various fields and improve the performance, and it is an emerging technology which is used in all industries to improve productivity and performance (Brouwer 2015).

\subsection{Artificial Intelligence (AI) in Finance}

Artificial Intelligence (AI) is leading the financial service by super. Mostly now days every financial sector is using Artificial Intelligence (AI) to avail the benefits like saving time, reducing cost and adding value to the business process. Some of the other uses of Artificial Intelligence (AI) in finance include fraud detection, increased security, spending pattern prediction, stock broker system client side user authentication (Patel2018).
(AI) may be dated back to 1956 when John McCarthy and Marvin Minsky presented The Logic Theorist as the first Artificial Intelligence (AI) programme at the Dartmouth Summer Research Project on Artificial Intelligence (DSRPAI). Their definition of AI referred to the ability of machines to understand, think, and learn in a similar way to human beings, indicating the possibility of using computers to simulate human intelligence. John McCarthy defined Artificial Intelligence (AI) as the science and engineering of making intelligent machines, especially intelligent computer programs. $\mathrm{AI}$ is a branch of science that helps machines finds the right solution for solving complex problems in a human-like way (Kasemsap, 2017).

McCarthy used the term Artificial Intelligence (AI) to distinguish it from machine thinking that included cybernetics, automata theory and complex information processing.

\subsection{Artificial Intelligence (AI) in Marketing}

Marketing enables a business to create and maintain long lasting and ever present relationship with the target audience. Artificial intelligence will define how digital marketing will be conducted now and in the future. The ways that has transformed artificial intelligence technology in changing the world of digital marketing are Marketing Increasingly Focused on Consumer Behaviour, Predictive Marketing, Lead Generation, Chatbots, Automated Content Creation, Image recognition, Email Marketing, Augmented Reality ( Murgai,2018).

\subsection{Artificial Intelligence (AI) in Healthcare}

According to a 2016 report from CB Insights, around $86 \%$ of the various health care organizations 
are currently using Artificial Intelligence (AI) technology. The most common ways in which AI is changing health care are by maintaining medical records and other data doing repetitive jobs, Treatment Design, Digital Consultation, Virtual Nurses, Medication Management, Drug Creation, Precision Medicine, Health Monitoring, Health Care System Analysis.(Swetha,2019)

\subsection{Artificial Intelligence (AI) in Supply} Chain and Logistics Management

The application of Artificial Intelligence (AI) in Supply Chain and Logistics Management can assist the managers in two ways:-

1. Automating business operations, processes and actions so that they can operate without the need of human intervention.

2. Assisting the human decision making process in day to day operations by reducing errors.

The Artificial Intelligence (AI) techniques can be used to provide real time information from the raw data, building concrete plans to improve demand forecast and make autonomous decisions regarding the different processes that are performed in the warehouse, offering autonomous vehicles for logistics and shipping. Artificial Intelligence (AI) also helps to improve different areas of supply chain like supply chain transparency and route optimization.

Form, the above discussions, it can be seen that Artificial Intelligence (AI) finds its applications in almost every fields of business and Artificial Intelligence (AI) is exponentially increasing in Human Resource (HR) also. Recent developments in the field of Artificial Intelligence (AI) and Human Resource (HR) have heightened the need to led to bring out the Human Resource (HR) areas in which Artificial Intelligence (AI) has been implemented especially concerning the Indian context. While many organizations have purchased their BI software and are starting to use in many areas of their businesses and make substantial gains, but they have not taken advantage of this in Human Resource Management area. Executives view Human Resources more of a cost centre, and less of a strategic asset within their organizations (Kapoor, 2010). So far, however, there has been little discussion in this area. This research paper thus tries to present a valuable insight on intersection of Artificial Intelligence (AI) Human Resource Management (HRM).

\section{RESEARCH QUESTIONS}

This study was undertaken with a objective of investigating the following research questions:-

1. What are the Human Resource (HR) dimensions in which Artificial Intelligence (AI) finds its applications?

2. Why there is a growing need to embrace Artificial Intelligence (AI) enabled

\section{technologies in Human Resource Management (HRM)?}

\section{RESEARCH METHODOLOGY}

The study was primarily depended on secondary data as there was no primary research conducted. The research study is using the descriptive research design. The secondary data has been collected from research papers, publications, websites, HR blogs, and survey reports published by various research organizations.

\section{RESULT ANALYSIS AND FINDINGS}

\subsection{Application of Artificial Intelligence (AI) in Human Resource (HR)}

In early days primary duties of human resource were recording, maintenance and payroll. Over time other functions such as employee training, uniformity and well being were added to their task Later on recruitment and skilled workforce selection were added to their duties. Today, Human Resource Management (HRM) is presuming a more critical role than ever before. These days, not just that they are responsible for all task mentioned, but they are also responsible for motivating the employees' wellbeing and workforce development as well. The Human Resource (HR) groups have more date at their fingertips than ever before. In recent times, organisations not only have the traditional roles but they also expertise in areas such as data science, data visualization and learning. Advancements in information technology (IT), predictive analytics, artificial intelligence and machine learning in HR processes is enabling professionals to perform traditional practices with much more ease and reduced time span. The HR executives are planning to invest in areas such as predictive analytics, enhanced process automation and Artificial Intelligence (AI) (Rao 2019).The future of Human Resource (HR) is both digital and human. As the influence of Artificial Intelligence (AI) is expanding to a greater extent in Human Resource Management (HRM), HR leaders are focusing to balance this advancement with technology.

\subsubsection{Recruitment and Talent acquisition}

One of the most critical decisions facing the workplace is recruitment and talent acquisition. The recruitment manager dedicates most of the working time to the development of recruitment process, which calls for technology shills, highly specific experience and leadership roles. While traditional Applicant Tracking System (ATS) were regarded as the backbone of agile recruiting, the changing workforce demographics and heightened candidate expectations have compelled the organizations to 
reimagine their recruiting process. The application of Artificial Intelligence (AI) for recruiting is empowering the organizations to streamline and modernize their recruiting efforts by reducing or eliminating human intervention in time consuming activities like manually screening resumes. Talent acquisition software has eliminated almost $75 \%$ of the work related to the recruitment process (Wislow, 2017). Using a preliminary assessment to screen out the potential candidate is critical task and a long process especially when the volume of data is high. The success of talent acquisition lies in building the relationship that converts potential candidates to employees. The power of Artificial Intelligence (AI) lies in its ability to process and manage high volume of data at fast speed, thus improving efficiency and productivity of organization. These same features and benefits can be applied to the hiring process. Artificial Intelligence (AI) algorithms can analyse the job description, tokenize the keywords and then analyse each candidate's profile to match the required job title, skill, experience, qualification etc.

\subsubsection{Training and development}

The need for training, orientation and support throughout the initial time with the company for a new employee is the cornerstone of success of any company. Training is equally important for the existing and as well as new employees. It enables to integrate new employees into the company and helps them settle into the rhythm of the company and adapt to new roles and routines. According to a research study by Oracle, nearly $27 \%$ of HR leaders think that AI-powered solutions for employee training will have a positive impact on employee Learning and Development (Gautam, 2019). Artificial Intelligence based training module ensures that the training programs are tailored to cater specific need of the employees. Artificial Intelligence (AI) infused with employee training program platform provides greater automation, personalization and better career and professional development. Artificial Intelligence (AI) enabled training modules are designed to provide broadest possible spectrum of procedure, protocols, policies and resources to address their problems and provide real time solution for the same. The new employees may refer to the Artificial Intelligence (AI) driven automated database system to clarify their doubts thus relieving the senior employees. With the constant digital disruption, Artificial Intelligence (AI) may also assist the employee in reskilling and upskilling. This will serve a two way benefit. For organizations, benefits include enduring workforce. For employees the benefits include career and professional development.

\subsubsection{Performance Management}

Performance feedback and appraisal are an integral and indispensable part of a workplace environment. The traditional methods of performance appraisal are not so reliable in the present era a technology as they may suffer from personal biasness. Thus, it is important to deploy a data driven culture where tools such as Artificial Intelligence (AI) may be collaborated with business leaders' opinion to assess the employee performance. Artificial Intelligence (AI) may make use of descriptive and predictive data analysis techniques to evaluate and analyse employee data such as employee engagement, performance data, rate of absenteeism etc. to make a clear distinction between high performer and high potential employees.

\subsubsection{Decision Making}

Human Resource Management (HRM) is all about making decisions. Like the other functional areas of an organization, Human Resource management (HRM) have to deal with making decisions oriented at the growth and profitability of the firm.

Some of the decisions may be complex in nature which requires deep understanding of the problem, detail information of the subject, critical thinking and a structured approach. With the combination of knowledge base and Artificial Intelligence (AI), it is possible to create sophisticated database models and stimulation as basis for decision making.

\subsection{Growing importance of Artificial Intelligence (AI) in Human Resource (HR)}

Artificial Intelligence (AI) at the forefront is transforming the business and commerce across the globe with larger organization embracing the change. With the continuous rejuvenation of Artificial Intelligence (AI) into Human Resource (HR), the traditional practices of the past are considered to be obsolete. As the next wave of cognitive, automated and immersive technologies changes the way we do business, experts state AI has the potential to transform HR (Ghaswalla, 2020). Thus, there was a growing need to evaluate the Human Resource (HR) practices in the light of technology which have the potential to drive Human Resource (HR) function from providing strategic advantage to supporting the work force. The researcher has identified and cited the following primary reasons for implementing Artificial Intelligence (AI) in Human Resource (HR):-

\subsubsection{Accelerate competitive advantage}

To stay ahead of the competition, businesses need to continuously monitor their competitors' move and adjust accordingly. The realm of Artificial Intelligence (AI) in Human Resource (HR) provides new insights, transform decision making, identifies competitor's strength and weakness and results in improved business outcome. Far sighted companies' sees investment in Artificial Intelligence (Al) as creating a significant business values, thus providing a competitive edge on the business front. 


\subsubsection{Acquisition and Development of new skills}

As the modern landscape of the business is defined by technology, the companies are looking forward to invest in new tools and practices for educating and training their employees. Artificial Intelligence (AI) enables Human Resource (HR) professionals to use predictive analysis using natural language for addressing skills related gaps of employees and connects them with learning to build those skills that are increasingly in demand.

\subsubsection{Improve employee experience}

As the world has been watching the unfolding of digital transformation in every sphere of life, employees expect a personalized experience at work. With the talent pipelines becoming complex, it is Important to know the pulse of the employees. Employees expect for relevant, contextual and convenient things that may be customized according to their preference and circumstances. Artificial Intelligence (AI) assists business leaders to fix this issue by meeting four criterions- clarification, compliance, connection and culture. The wide spectrums of overlapping of data with Artificial Intelligence (AI) enable technology are effective for improving employee experience at the individual level.

\subsubsection{Efficient use of Human Resource Budgeting}

The Human Resource (HR) budgeting decisions are extremely complex as it determines the long term economic and financial profitability of the business. As contrast to the one-size-fits-all approach that worked in the past, the Human Resource (HR) manager now rely on Artificial Intelligence (AI) driven algorithms to take accurate decisions regarding budgeting and resource allocation. The primitive advantage of Artificial Intelligence (AI) driven decisions is that the information is based on facts and statistical figures subjected to a simple set of calculations.

\subsubsection{Mental Health}

The human based task makes the Human Resource (HR) department a crucial element within any organization. As the relationship between employer and employee are thriving both at professional and personal sphere, the role of Human Resource (HR) have shifted from product oriented to people centric approach. The domain of Human Resource (HR) professional now range from counselling, mentoring, providing moral support securing the mental health of the well being at the workplace. Prolong working hours; changing business dynamics, changing business roles, pressure to meet the project deadlines are some of reasons which have raised the concern to track the mental health of the workforce. Artificial Intelligence (AI) based techniques such as sentiment analysis may be used to correlate to employee morale and can help organizations in identifying employees suffering from disruptive mental state of mind. AI-enabled wearable tools, for instance, built with deep learning models, voice and image recognition and natural language processing can analyze and monitor employee behaviour and emotions. This helps to identify workers who are struggling with job tasks or battling with mental illnesses such as anxiety and depression (Okhifun, 2020).incorporating information in Artificial Intelligence (AI) enabled frameworks about the warning signs of poor mental state of an employee would allow Human Resource (HR) department to extend additional support.

\section{CONCLUSION}

Artificial Intelligence (AI) provides an impressive way of application in a wide range of area. The inclusion of Artificial Intelligence (AI) in business has opened doors to limitless opportunities. The future holds infinite possibilities for Artificial Intelligence (AI) especially when it comes to play in the field of Human Resource (HR). It cannot be denied that Artificial Intelligence (AI) aid and abet a Human Resource (HR) manager in carrying out different functions effectively and efficiently thus enabling them to focus on higher value task .But this not the stage where Artificial Intelligence (AI) can replace human beings. Right from recruitment to performance management there are administrative and repetitive in nature. The complexity of Human Resource (HR) and its multitude of variables add butter oil to burning flame. Digitalization and automation of work in Human Resource (HR) provides integrated orientation, experience and real time solution. The integration and adoption of Artificial Intelligence (AI) has transfigured the role of a Human Resource (HR) manager from manual administrative task to a more strategic approach.

Although Artificial Intelligence (AI) is foreseen as an opportunity and is regarded as a game changer for business to gain competitive advantage, it also offers certain challenges (Bersin, 2017) which a company need to overcome to avail the full advantage of it. At the outset, the initial challenges to deal with the redundancy of the data. As the Human Resource data is stored at multiple locations which is required by different departments, any changes in one set of data may not be reflected in other set thus acknowledging the problem of data inconsistency. The second concern is to deal with the policy of data security and confidentiality. The companies employing AI enabled technologies should take the employees in confidence that there data would not be misguided and measures should be taken to safeguard their data and prevent it from unauthorized access. Lastly, as Artificial Intelligence (AI) embedded programs and algorithm works on data collected and 
captured by human one cannot rely on its accuracy. These algorithm help to reduce human intrudiction, but their results may not be 100 percent valid and acceptable in every decision. Despite of the challenge discussed above most of the researchers believes that the futures of business is both Human Resource (HR) and digital and are viewing Artificial Intelligence (AI) as a driver for change towards the light at the end of the tunnel.

\section{REFERNCES}

1. Archer, N. \& Yuan, Y. F. (2000) Managing business-to-business relationships throughout the e-commerce procurement life cycle. Internet Research-Electronic Networking Applications and Policy, 10, 385- 395.

2. Bersin, J. (2018). How will AI in HR be a gamechanger? Retrieved from https://searchhrsoftware.techtarget.com/opinion/ How-will-AI-in-HR-be-a-game- changer

3. Biswas, S. (2018). Employee Experience, Jobs and Skills: How AI will Impact HR. Retrieved fromhttps://www.hrtechnologist.com/articles/digi tal-transformation/employee-experience-jobsand-skills-how-ai-will-impact-hrl

4. Bloem J, Van Doorn M, Duivestein S, Excoffier $D$, Maas R, Van Ommeren E (2014) The Fourth Industrial Revolution. Things Tighten.

5. Gautam,A.(2019). How Artificial Intelligence Can Transform Employee Training In 2020 And Beyond. Retrieved from https://elearningindustry.com/how-artificialintelligence-transforms-employee-training

6. Ghaswalla, N.A. (2020). How Artificial Intelligence transforming employee experience. Retrieved from https://www.thehindubusinessline.com/infotech/how-artificial-intelligence-transformingemployee-experience/article30607509.ece\#

7. Meade, J. (2017).Is Your Business Ready for Artificial Intelligence (AI)? Retrieved from https://towardsdatascience.com/is-your-businessready-for-artificial-intelligence-ai-51 efefb11d97

8. Kapoor, B. (2010). Business Intelligence and Its Use for Human Resource Management. The Journal of Human Resource and Adult Learning, 6(2), 21-30.

9. Kasemsap, K. (2017). Artificial intelligence: Current issues and applications. In Handbook of research on manufacturing process modelling and optimization strategies (pp. 454-474). IGI Global.

10. Klosters, D. (2016).World Economic Forum Annual Meeting 2016 Mastering the Fourth Industrial Revolution. World Economic Forum. Retrieved http://www3.weforum.org/docs/Medial.

11. Manager, W. (2018). 7 Ways to Use Artificial Intelligence in HR. Retrieved from https://www.newgenapps.com/blog/growing-roleof-artificial-intelligence-in- $h r$

12. Manyika, J., Chui, M., Miremadi, M., Bughin, J.; George, K., Willmott, P., \&. Dewhurst, M. (2017,
January). "A Future that Works: Automation, Employment, and Productivity." McKinsey\&Co. Retrieved from https://www.gita.org.in/Attachments/Reports/MG I-A-future-that-works-Full-report.pdf

13. Murgai, A. (2018). Transforming Digital Marketing with Artificial Intelligence. Retrieved from

https://www.ijltemas.in/DigitalLibrary/Vol.7Issue 4/259-262.pdf

14. Okhifun, G. (2020). How Artificial Intelligence Can Tackle Workplace Stress. Retrieved from https://www.corporatewellnessmagazine.com/arti cle/how-artificial-intelligence-can-fight-againstworkplace-stress

15. Park SC (2017) The Fourth Industrial Revolution and implications for innovative cluster policies. AI \& Society 33(3). pp 433-45.

16. Patel, K. (2018). Artificial Intelligence In Finance. Retrieved from https://www.researchgate.net/publication/335109 921_Artificial_Intelligence_In_Finance

17. Rao, P. (2019). The future is now: The changing role of HR. Retrieved from https://economictimes.indiatimes.com/smallbiz/hr-leadership/leadership/the-future-is-nowthe-changing-role-ofhr/articleshow/68229542.cms

18. Serafini, L.; Garcez, A.A. (2016). Logic Tensor Networks: Deep Learning and Logical Reasoning from Data and Knowledge. Retrieved from http://ceur-ws.org/Vol-1768/NESY16_paper3.pdf

19. Trkman, P. (2010). The critical success factors of business process management. International journal of information management, 30(2), pp.125-134.

20. Wislow,E.(2017).Beworkhappy.com.Retrievedfro mhttps://www.facebook.com/beworkhappy. 